\title{
RETÓRICA E IMAGEN IMPERIAL EN LA OBRA DE LOS EPITOMADORES Y PANEGIRISTAS DEL SIGLO IV
}

\author{
RHETORIC AND EMPEROR'S IMAGE \\ IN THE LATIN EPITOMISTS AND PANEGYRISTS \\ OF THE FOURTH CENTURY
}

\author{
Guadalupe Lopetegui \\ $U P V / E H U$ \\ guadalupe.lopetegi@ehu.eus
}

DOI: $10.1387 /$ veleia.14975

\begin{abstract}
Resumen: El objetivo de nuestro trabajo es analizar los principales recursos retóricos utilizados por los epitomadores y panegiristas del siglo IV para subrayar la efectividad de la retórica como instrumento de propaganda ideológica en géneros literarios diversos. En resumen, nos proponemos demostrar que tanto historiadores como panegiristas contribuyeron, si bien en distinto grado, a modelar una imagen determinada de los emperadores y a transmitir una ideología concreta a través de su arte narrativo.

Palabras clave: Retórica, epítome, panegírico, propaganda.

Abstract: Our aim in this paper is to analyze the main rhetorical devices which are used by the epitomists and the latin panegyrists of the fourth century in order to emphasize the effectiveness of rhetoric as an instrument of propaganda within different literary genres. Briefly, we intend to prove that historians and panegyrists contributed, albeit in an unequal way, to shapen a certain image of the emperors and to transmit a specific ideology through their narrative art.
\end{abstract}

Keywords: Rhetoric, epitome, panegyric, propaganda.

Recibido: 17-04-2015 Informado: 14-05-2015

Definitivo: 29-05-2015

\section{INTRODUCCIÓN}

Según señala J. Matthews (Marincola 2007, 291), parece que Jerónimo conoció una edición conjunta de los Anales y las Historias de Tácito titulada Vidas de los Césares en 30 libros. Este dato demuestra que para un intelectual como Jerónimo y probablemente para los lectores de la época, la obra histórica de Tácito, fuera cual fuese el propósito del autor, presentaba ya la historia de la primera etapa imperial como una sucesión de los emperadores que la gobernaron. Suetonio con sus biografías corroboraría posteriormente esta tendencia de modo que la precisión cronológica y el método analístico propios de la narrativa historiográfica en adelante perdieron protagonismo en fa- 
vor de una presentación de los acontecimientos más bien temática y centrada en las grandes figuras. Esta tendencia es la que siguen también los llamados epitomadores del s. Iv: Eutropio, Aurelio Víctor y el anónimo autor del epítome De Caesaribus.

Debido a la situación de cuasi vacío literario que se produce en la mayor parte del siglo III por lo que hace a la producción literaria escrita en latín, los epitomadores citados son la fuente histórica principal para el período de la primera Tetrarquía ya que una cuarta fuente digna de mención, la Historia Augusta, comprende la etapa que se extiende desde Heliogábalo hasta Caro y Carino, predecesores de Diocleciano. Por lo demás, la información suministrada por los autores citados se complementa habitualmente con otro tipo de fuentes, tanto literarias (así por ejemplo, el epistolario de Cipriano, obras de Lactancio, Orígenes, Plotino o Porfirio) como legales (principalmente el Digesto) y numismáticas.

Nuestro objetivo en este trabajo es analizar los recursos retóricos que caracterizan la técnica narrativa de los epitomadores del siglo iv así como la imagen que a través de tales recursos ofrecen de los tetrarcas. A continuación, confrontaremos dicha imagen con la que modelan los autores de los PL, el corpus más importante que se nos conserva de literatura panegírica en latín. Aunque las fuentes historiográficas no son equiparables a los discursos de los panegiristas en lo que hace a la transmisión del contenido histórico, la literatura secundaria ha reconocido la validez de tales escritos adulatorios para analizar el contexto ideológico, político y cultural de la época. Además, epitomadores y panegiristas comparten en mayor o menor grado el uso de toda una serie de recursos elocutivos y estrategias discursivas. Este uso de la retórica les permite conformar una imagen interesada de los personajes y transmitir así su interpretación particular de los acontecimientos narrados. De Aurelio Víctor, por ejemplo, se ha destacado su abundante uso de reflexiones morales y anécdotas (Dufraigne 2003, XLVIII-XLIX) así como una marcada voluntad de imitar el estilo de predecesores tan ilustres como Salustio y Tácito (Bird 1984, 90-99). Eutropio, caracterizado por un estilo más sobrio, conciso y homogéneo que el de A. Víctor, presenta una exposición general de los hechos esenciales del período con una mayor preocupación por ofrecer información fiable y objetiva (Falque 1999, 25-28). En cualquier caso, en ambas fuentes históricas la retórica condiciona decisivamente la imagen de los emperadores y la interpretación de los hechos atribuidos a los mismos.

Por lo que hace a los panegiristas, a los que Amiano Marcelino cita como fuente histórica (Res gest., 31, 10,5), su inclusión en este trabajo se debe a que constituyen claros ejemplos de instrumentalización de la retórica al servicio de la propaganda imperial (Lomas 1988; Rodríguez Gervás 1991; Mause 1994 y Ronning 2007) y, desde esa perspectiva pueden servir de contrapunto para confrontar la imagen idealizada que ofrecen con la supuestamente más objetiva de las fuentes históricas. En definitiva, nos proponemos subrayar los procedimientos retóricos que historiadores y panegiristas consideran más efectivos, en nuestra opinión, para transmitir una determinada imagen de los emperadores y divulgar los principales lemas de la propaganda imperial.

\section{ReCURSOS RETÓRICOS EN LOS EPITOMADORES DEL SIGLO IV}

\subsection{El De Caesaribus de Aurelio Victor}

Como afirma Dufraigne (2003, XXXV-XXXIX), el valor histórico del De Caesaribus es discutible ya que el autor concede prioridad a las inquietudes de orden literario sobre las estrictamente históricas de manera que «le goût du pittoresque l'emporte chez lui sur le sens de l'histoire» (ibid., 
XXXVI). Son precisamente dichas inquietudes las que hacen de su obra un producto literario interesante para nuestro objetivo y ello a pesar de la desigual presentación de los emperadores más emblemáticos y de las limitaciones impuestas por el subgénero del breviario ${ }^{1}$.

Parece que la obra se compuso en un período breve de tiempo, entre finales del 359 y septiembre del 360. Con todo, no se trata de una aséptica sucesión de biografías narradas en un tono impersonal y supuestamente objetivo. Dada la cantidad de digresiones y comentarios de contenido moralizante o político que jalonan la narración, no es difícil captar el sesgo interesado con el que perfila el historiador los personajes de su relato. Sin duda, el Libro de los Césares incurre en los vicios de los que debería alejarse el historiador ideal descrito por Luciano en su opúsculo De conscribenda historia ${ }^{2}$. El Breviario de Eutropio presenta, en este sentido, un relato más comedido, coherente y cercano a la objetividad histórica, encauzado a través de un estilo sencillo y conciso que contribuyó a su éxito en siglos posteriores. Sin embargo, el retoricismo de Aurelio Víctor se revela especialmente interesante para nuestro propósito, en especial por la abundante presencia de digresiones a lo largo de todo el relato.

Tal como han señalado diferentes estudiosos de la obra, algunas de las digresiones cumplen, entre otras funciones, la de delimitar los seis períodos históricos que se pueden establecer en el curso de la narración (Dufraigne 2003, XLI-XLII; Falque 1999, 169-170; Cizek 1995, 292).

Para analizar la imagen de la Primera Tetrarquía nos vamos a detener en el sexto y último período de los seis a los que nos hemos referido, a saber, el que se extiende desde Caro hasta Constancio II. En las líneas que siguen nos proponemos señalar los recursos retóricos que modelan la presentación de los personajes y de los hechos y contrastar a continuación la imagen conformada con la que ofrece Eutropio en los capítulos correspondientes de su Breviario.

En principio cabe señalar que la sucesión de las seis etapas no se caracteriza por la regularidad en lo que hace a la extensión temporal de las mismas y a la abundancia y carácter de los excursos que se insertan en ellas. Con todo, por lo que hace a los tres últimos períodos (de Nerva a Alejandro Severo; de Maximino a Tácito y de Caro a Constancio II) sí podemos afirmar con Dufraigne que «font l'objet de développements sensiblement égaux» (2003, XLIV). El reinado de Diocleciano, precedido por el de Caro y sus hijos constituye el momento álgido del sexto período, cuyo inicio, por otra parte, se marca con una digresión $(37,5-7)$. Tanto ésta como la que el historiador sitúa al final del cuarto período y antes del inicio de la anarquía militar (24, 8-11) no constituyen meros adornos retóricos. Llegados a este punto queremos insistir en la función de los excursos en la obra de Aurelio Víctor ya que se trata, como hemos señalado, del elemento retórico más destacable de la misma. En primer lugar, hay que decir que la mayoría de las digresiones no es-

1 Para la diferencia entre epítome y breviario vid. Cizek 1995, 285-287 y Moreno 1997, 700-709. Frente a la opinión de E. Falque en la introducción a la traducción de la obra (1999, 169), creemos con Dufraigne (2003, XLI) que el De Caesaribus de Aurelio Víctor debe considerarse un "breviario» (una visión de conjunto de la historia romana desde los orígenes a partir de fuentes diversas) y no un epítome (resumen de una obra ya existente). Tal como subraya el editor francés, el título de las fuentes manuscritas (Historiae Abreviatae) sugiere dicha idea si bien la palabra breviarium es evitada por el autor probablemente porque su obra ofrece una historia del período imperial y no un relato desde los orígenes.

\footnotetext{
2 En su conocido opúsculo de estructura epistolar Luciano arremete irónicamente contra los historiadores contemporáneos por hacer uso del elogio y del vituperio así como del mito y otros recursos propios de la poesía. Entre los consejos que dirige a los futuros historiadores destacan, sobre todo, el de salvaguardar la independencia ideológica, respetar la objetividad e imparcialidad ante todo, evitar descripciones pictóricas y digresiones y hacer uso de un estilo claro, no excesivamente adornado con las armas de la retórica (Botella Zaragoza 1990, caps. 38-60).
} 
tán insertas de un modo aleatorio en el curso de la narración. Algunas de ellas marcan claramente unos puntos de inflexión y cumplen, por ello, una función delimitadora en la estructuración del relato a la vez que subrayan actuaciones o acontecimientos decisivos. Incluso podría decirse, en mi opinión, que se trata de elementos narrativos que contribuyen decisivamente a subrayar la técnica historiográfica adoptada por el autor, es decir, su opción de escribir un relato histórico y no tanto biografías imperiales. Y ello porque tales excursos, además de destacar rasgos específicos del período en cuestión, subrayan la sucesión cronológica de los hechos insertándolos en un continuum temporal que trasciende lo anecdótico y lo particular. Desde un punto de vista formal, el inicio de las digresiones que preceden los períodos quinto y sexto (caps. 24 y 37), aparece delimitado por una conjunción temporal y tras su finalización, el historiador continúa el relato de los hechos mediante una partícula de enlace con valor consecutivo. Lo mismo se observa en los excursos que preceden los reinados de Nerva, Maximino el tracio o Caro (períodos cuarto, quinto y sexto, respectivamente) ${ }^{3}$. Otras digresiones no tienen la función delimitadora que acabamos de mencionar. En el interior de cada etapa histórica numerosas reflexiones de mayor o menor extensión plasman las valoraciones del historiador o subrayan los momentos de máxima degradación moral en una concepción de la historia que, según veremos, se revela como cíclica. Así sucede en $33,4-5 ; 34,6-8$ o $35,13-14^{4}$.

Por lo que hace al contenido de los excursos con función delimitadora, Aurelio Víctor destaca los rasgos definitorios, en su opinión, del nuevo período que se inicia de modo que en las digresiones más breves que se insertan en los capítulos del periodo en cuestión se insiste en alguno de los rasgos aludidos. Más concretamente, en 24, 9-11 y 37, 5-7 el tema central es la pérdida de autoridad por parte del Senado para elegir y/o legitimar a los sucesivos emperadores los cuales, por otra parte, son gentes sin formación y de origen incierto que asumen el poder supremo con el apoyo de facciones del ejército. Las digresiones mencionadas se caracterizan por un estilo salustianeo que no es exclusivo de estos pasajes y que resulta perceptible tanto en el estilo como en el tono moralizante. En este sentido, hay que recordar que la obra de Salustio tuvo una gran influencia en la visión de la historia romana propia de los autores tardo-antiguos (Bird 1984, 91; O’Gorman 2009, 379). Las caracterizaciones de Catilina o Iugurtha como personificaciones de una naturaleza libidinosa, corrupta e insaciable así como su visión pesimista del ser humano, arrastrado por los vicios y zarandeado por la fortuna, dejaron una huella perceptible en autores posteriores. Aurelio Víctor adopta, además de motivos y recursos narrativos, el estilo arcaizante y antitético de Salustio, marcado por la presencia de construcciones disyuntivas y conceptos opuestos (Otón 2002, 363-389). La descripción del caos político y social que el epitomador asocia con el advenimiento al poder de los emperadores-soldado remite a los tópicos con los que Salustio describe en sus monografías la tendencia destructora de la naturaleza humana cuando es arrastrada por la cupiditas y la libido imperii ${ }^{5}$. Así, en 24, 9-11 el autor subraya los elementos del período venidero que considera defini-

3 Vid. tras Domiciano en 11, 12-12,1: Hactenus Romae seu per Italiam orti imperium rexere....Quid enim Nerva; tras Alejandro Severo y antes de Maximino 24,9-25,1: Abhinc, dum dominandi suis....Namque Gaius Iulius Maximinus; finalmente, tras el asesinato de Galieno y antes de Caro 37,5- 38,1: Abhinc militaris potentia convalvit....Igitur Carus.

${ }^{4}$ Quod factum praecipue edocuit cuncta in se orbis modo ueri, nibilque accidere quod rursum naturae uis ferre nequeat aeui spatio; adhuc uirtutibus principum res attolli facile uel aflictas easque firmiores praeceps vitiis dari.

5 Es característico en los prefacios de sus monografías el uso de conceptos antitéticos organizados en construcciones binarias, reflejo quizá de una concepción empedoclea del acontecer humano. Aurelio Víctor hace uso de los mismos tópicos éticos con los que Salustio explica la decadencia de Roma: cf. e.g. Cat. VI,7 (Post ubi regium imperium quod initio conservandae libertatis atque angendae rei publicae fuerat, in superbiam domina- 
torios y decisivos a la vez que valora tales hechos concretos enmarcándolos en una visión histórica que contempla el devenir de la historia de Roma a través de las etapas de la vida humana: Roma crece y alcanza su momento de máxima prosperidad con Septimio Severo y Basiano e inicia a partir de ese punto una decadencia imparable:

Neque ultra annos tredecim imperio functus, rempublicam reliquit firmatam undique (Aurelius Alexander). Quae iam tum a Romulo ad Septimium certatim euolans, Bassiani consiliis tanquam in summo constitit. Quo ne confestim laberetur Alexandri fuit. Abhinc, dum dominandi suis quam subigendi externos cupientiores sunt atque inter se armantur magis, Romanum statum quasi abrupto praecipitauere immissique in imperium promiscue boni malique, nobiles ignobiles ac barbariae multi $(24,7-9)$.

La concepción cíclica, por otro lado, se destaca explícitamente en la digresión que tiene lugar en 35, 12-14 tras la muerte de Aureliano (emperador entre el 270-275):

Tantum ille vir (Aurelianus) seueritate atque incorruptis artibus potuit ut eius necis auctoribus exitio, prauis metui simula ac dubiis optimo cuique desiderio, nemini insolentiae aut ostentationi esset; atque etiam, quasi soli Romulo, interregni species obuenit, longe uero gloriosior. Quod factum praecipue edocuit cuncta in se orbis modo uerti, nibilque accidere quod rursum naturae uis ferre nequeat aeui spatio; adhuc uirtutibus principum res attolli facile uel afflictas easque firmiores praeceps uitiis dari.

Después de un largo período de barbarie que alcanza su punto culminante con Galieno, las virtutes de un buen emperador como Aureliano hacen posible la instauración de un breve interregno, tal como ocurrió en los tiempos antiguos tras Rómulo; incluso el Senado recupera la prerrogativa para elegir emperador. Pero el aparente inicio de un nuevo ciclo se trunca ya que, tras un brevísimo período, el poder militar vuelve a imponerse definitivamente y se inicia la última de las etapas históricas con Caro $(37,5-7)$. El factor definitorio del último de los períodos descritos es precisamente el dominio absoluto del poder militar sobre el Senado: Abhinc militaris potentia conualuit ac senatui imperium creandique ius principis ereptum ad nostram memoriam, incertum an ipso cupiente per desidiam an metu seu dissensionum odio.

Como puede advertirse, las digresiones, además de marcar los distintos períodos históricos, tienen la función de subrayar los momentos álgidos tanto de la decadencia como de la prosperidad de modo que el acontecer histórico se presenta como una sucesión de cuadros que contrastan por el predominio de actos marcados por la virtud o por los vicios. Así, en el período comprendido entre Maximiano y Tácito, la curva decadente alcanza la máxima degradación con Galieno y así lo destaca el historiador: rem Romanam quasi naufragio dedit (33,3); proinde cuncta ad extremum reciderant, uti talibus imperia ac uirtutum omnium decus ludibrio essent $(33,10)$ y sobre todo la digresión 33, 23-27 en la que Aurelio Víctor subraya la utilidad del testimonio histórico para reivindicar el

tionemque se convortit, inmutato more annua imperia binosque imperatores sibi fecere) o Iugurtha, 41, 9 (Ita cum potentia et avaritia sine modo modestiaque invadere, polluere et vastare omnia...quoad ipsa precipitavit semet) y A. Victor De caesaribus, 24, 9 (Abhinc dum dominandi suis quam subigendi externos cupientiores sunt atque inter se armantur magis, Romanum statum quasi abrupto praecipitauere immissique in imperium promiscue boni malique). Por otro lado, la idea de la virtud como un muro que defiende al hombre para no caer en manos de la Fortuna aparece en Juvenal, Sat. X, 363-364 (semita certe/tranquillae per virtutem patet unica uitae/nullum numen habes, si sit prudentia: nos telno facimus, Fortuna, deam caeloque locamus). 
recuerdo imborrable de las actuaciones virtuosas frente a las deshonestas ${ }^{6}$. Los emperadores que representan los momentos culminantes de cada período, tanto si son de expansión como de decadencia cuentan con una descripción especialmente extensa (Septimio Severo, Galieno y, en el último período, Diocleciano) en la que los tópicos retóricos propios de la técnica biográfica (loci a persona organizados generalmente per species) son manipulados al servicio de la narración histórica. Con ello queremos subrayar que, si bien el epitomador plantea la sucesión de la historia imperial a través de las biografías de los emperadores, generalmente prima la visión cronológica de los hechos y una relación de causalidad entre los mismos a través del análisis de la moralidad o inmoralidad de los principales «agentes», es decir, los emperadores. En este sentido, las digresiones constituyen, en nuestra opinión, el principal elemento retórico para fusionar la técnica biográfica y la histórica. Hasta tal punto condicionan el curso de la narración que en ocasiones el esquema biográfico y la sucesión cronológica se alteran al servicio de la interpretación personal que el historiador ofrece a través de tales digresiones. Así por ejemplo, tras el relato de la ascensión al poder de Septimio Severo, Aurelio Víctor narra en primer lugar el modo como llega al poder y castiga a los asesinos de Pertínax (20,1-3). Pero, al referirse a Salvio Juliano y a su formación jurídica, inicia una digresión en torno a la importancia de la educación y la formación en las artes liberales. Considera esta circunstancia como un factor de importancia vital en su tiempo ya que se trata, en su opinión, de la vía principal para ascender en el cursus honorum. En dicha digresión se cita a sí mismo como ejemplo de éxito social y subraya el prestigio alcanzado por el propio Septimio Severo, prestigio confirmado por los honores recibidos tras su muerte. Relata, por tanto, tales honores y la razón del apelativo de Severo mediante una nueva digresión. Después de ésta, introduce ya la descripción de las virtutes y la enumeración de los principales logros políticos del emperador, sus aficiones culturales y su muerte. Inserta una referencia a su origen humilde, su formación y llegada al poder imperial y continúa después relatando los honores recibidos post mortem y el paso del poder imperial a sus hijos. Este ejemplo de esquema biográfico «deslavazado» demuestra claramente que la interpretación de los hechos a través de digresiones y comentarios personales es el ingrediente narrativo principal de la obra de Aurelio Víctor y el que, sobre todo, permite considerarlo como historiador y no como mero epitomador.

Un segundo recurso retórico que añade un colorido particular a la narración de los hechos en el De Caesaribus es el uso de la evidentia, es decir, la descripción vívida y dramatizada de los hechos, si bien su presencia no es tan notoria ni tan decisiva como en el caso anterior. El uso de la misma está asociado al gusto por la inserción de anécdotas para dar colorido y verosimilitud a la narración. Un ejemplo claro en el período que nos concierne es el pasaje 39, 13 donde el historiador describe el asesinato de Apro por parte de Diocleciano en su primera alocución pública ante el ejército tras ser nombrado emperador ${ }^{7}$.

Seguidamente vamos a referirnos a la estructura del capítulo 39 (correspondiente básicamente a Diocleciano) para mostrar el papel que desempeñan en el mismo los recursos retóricos citados y la imagen que a través de ellos se ofrece de la Tetrarquía.

${ }^{6}$ Quin etiam aliquanti pari libidine in caelestium numerum referuntur aegre exsequiis digni. Quis ni fides gestarum rerum obstitisset, quae neque honestos praemiis memoriae frustrari sinit neque improbis aeternam illustremque famam procedere nequiquam peteretur virtus cum verum illud atque unicum decus pessimo cuique gratia tribueretur demptum impie bonis (33, 25-26).

7 Con respecto a la evidentia, un recurso abundante y característico de los panegíricos comentados a continuación, vid. la nota 24. 


\subsubsection{La imagen de Diocleciano y la Tetrarquía en el De Caesaribus}

En primer lugar, cabe señalar que en el capítulo 39 el historiador no aborda desde el inicio la biografía de un nuevo emperador sino que continúa con el relato de los hechos referentes al reinado de Caro y su hijo Numeriano y en el curso de los mismos inserta la figura y acciones de Diocleciano. Así, la putrefacción del cadáver de Numeriano y su descubrimiento constituyen el hecho previo al nombramiento del nuevo emperador. La presentación de su semblanza, al igual que la de otras figuras de peso tales como Nerva o Septimio Severo, no responde a los esquemas habituales de una vita al estilo suetoniano: los tópicos a persona y la distribución temática de los facta propios del personaje no están elaborados de un modo sistemático. Lo que prima en el relato del historiador, como ya hemos dicho, es la relación cronológica de los hechos amplificados con digresiones interpretativas y la caracterización de la personalidad de los emperadores a través de los facta que llevan a cabo. Sólo al final del capítulo y tras ofrecer un panorama de los acontecimientos del período y de la actitud de los personajes centrales en los mismos, se recurre al esquema biográfico y se reúnen temáticamente las aportaciones principales de los tetrarcas. Aunque el resultado es a veces un tanto caótico, la fusión de la técnica biográfica con la historiográfica le permite ofrecer un retrato vívido y hasta dramático, debido a que la narración consiste en una sucesión de hechos situados en escenarios diversos y a que en ocasiones hace uso de la evidentia. Para introducir el nombramiento de Diocleciano como emperador Aurelio Víctor describe en primer lugar, un hecho funesto, a saber, la putrefacción del cadáver del joven Numeriano y, tras relatar la elección de un nuevo emperador por parte de los soldados, ofrece una primera imagen del mismo: Valerius Diocletianus...ob sapientiam deligitur, magnus vir, his moribus tamen $(39,1)^{8}$. Frente a la denominación de sapiens, se destaca un aspecto externo que podría descalificar su imago: el lujo del que se revistió y el ceremonial que asoció a su condición de augusto, especialmente, el rito de la adoratio 9 . Esta primera imagen va seguida de una digresión acerca de la soberbia y la ambición de la que hacen gala los humillimi cuando acceden a una posición elevada si bien Aurelio Víctor rectifica al instante la tendencia a la soberbia que se podría atribuir a Diocleciano añadiendo a su condición de dominus la de parens patriae y remitiendo a sus facta: satisque constat prudentem uirum edocere uoluisse atrocitatem rerum magis quam nominum officere $(39,8)$. El primer hecho digno de mención es su comportamiento tras el asesinato de Carino a manos de sus propios hombres: tras su primer discurso ante el ejército y después de afirmar que no había buscado el imperium que el ejército le había concedido, mata a Apro, suegro y asesino de Numeriano. La descripción del hecho, un claro ejemplo de evidentia, permite al historiador reafirmar la justicia del mismo y, lo que es más importante, subrayar la clementia de Diocleciano para con los hombres de Apro. Una nueva digresión insiste en esta cualidad del emperador, cualidad que contrasta abiertamente con la valoración de Eutropio a este respecto (caps. 23 y 26) y con la imagen de crueldad que se encuentra en fuentes cristianas contemporáneas tales como Lactancio (De mort. Pers. 7, 1) u Orosio (Hist. 7, 25, 13). La moderación en la aplicación de las penas y en general, en su comportamiento le impulsó, según Aurelio Víctor, a introducir en el gobierno gentes extranjeras cuya aportación sería decisiva para

8 Las fuentes antiguas insisten, sobre todo, en la sagacidad y astucia de Diocleciano, vid. Eutropio 26,1 (D. moratus callide fuit, sagax praeterea et admodum subtilis ingenii) y la Historia Augusta 13, 1 (virum insignem, callidum, amantem rei p., amantem suorum et ad omnia quae tempus quaesiverat).

\footnotetext{
9 Al igual que Aurelio Víctor, también Eutropio y Amiano Marcelino consideran que Diocleciano habría inaugurado el rito de la adoratio (Ratti 1996, 367) aunque otros emperadores, concretamente, Cómodo y Heliogábalo habrían tenido la tentación de hacerse adorar en vida.
} 
proteger las fronteras del imperio ${ }^{10}$ : el nombramiento como augusto de Maximiano y el de los Césares Constancio y Galerio posteriormente, habrían respondido, según el historiador, a la necesidad de hacer frente con efectividad a conflictos e insurrecciones en las distintas zonas del imperio. Una nueva digresión en 26-29 refleja la valoración conjunta por parte del historiador de los emperadores de la primera Tetrarquía: provincianos, poco o nada cultos, de origen humilde pero con un carácter tenaz forjado por la milicia ${ }^{11}$. Además, la concordia entre ellos y la consideración de Diocleciano como padre supremo tuvo consecuencias favorables a la vez que evitó luchas civiles. Tras una valoración positiva de este sistema de gobierno, el epitomador menciona el reparto territorial entre los augustos y los césares así como los éxitos conseguidos en los distintos conflictos territoriales (28-31). En esta relación de hechos se mencionan explícitamente el triunfo sobre el rey Narseo y la victoria frente a Carausio a modo de exempla con el fin de probar la eficacia del poder imperial organizado del modo anteriormente citado (34-42) aunque sin hacer alusión al comportamiento de los augustos para con los vencidos. Seguidamente, Aurelio Víctor resume la labor de los tetrarcas en cuestiones de política interior en términos elogiosos; subraya como hechos especialmente favorables la supresión de los frumentarii y la regulación del funcionamiento de los cargos públicos con leyes más justas (44). Es destacable, por otro lado, el silencio del historiador en torno a la actuación de Diocleciano contra los cristianos o la dureza de la represión que llevó a cabo en Egipto según consta en otras fuentes. Para completar la semblanza de los augustos tras la exposición de los logros principales, se mencionan brevemente algunos vitia atribuibles a cada uno de ellos, especialmente a Maximiano y tras conjeturar sobre las razones de la abdicación de Diocleciano, termina el capítulo con un elogio del augusto por haber renunciado voluntariamente al cargo.

Se trata de un capítulo en el que, como afirma Dufraigne $(2003,190)$ la narración de los hechos, salpicada de digresiones se impone sobre un esquema más propiamente biográfico basado en la caracterización de los emperadores. A través de aquellas, Aurelio Víctor transmite una imagen elogiosa de un emperador caracterizado por la prudencia/sabiduría, por la moderación, la justicia y la equidad, capaz de ejercer un liderazgo presidido por la concordia. Las referencias a los éxitos militares, a la evitación de las luchas civiles, a la recuperación de los cultos religiosos antiguos, el restablecimiento de ciertas virtudes y el embellecimiento de Roma y de otras ciudades del imperio ofrecen una imagen de renovación y resurgimiento tras la anterior etapa de decadencia, etapa cuyos últimos vestigios están representados por Carino. Las digresiones y la selección de los acontecimientos narrados así como el uso de la evidentia o la mención de algún hecho anecdótico como el desfile de Narseo con su harén contribuyen a la conformación de esta imagen que, sin embargo, no aparece corroborada por otras fuentes en determinados aspectos (Ratti 1996, 367 ss.). Entre ellas sólo nos vamos a referir en las líneas que siguen a Eutropio, autor de un Breviario que tuvo una amplia difusión en los siglos posteriores.

\subsection{La caracterización de la Tetrarquía en el Breviarium de Eutropio}

La historia abreviada del período imperial de Eutropio presenta en mayor medida que Aurelio Víctor las características señaladas entre otros por Banehich para la tradición epitomadora (Marin-

10 Vid. sobre todo en 11, 12-13 los términos elogiosos en los que Aurelio Víctor se refiere a la aportación de los provincianos y extranjeros a la expansión romana.
11 His sane omnibus Illyricum patria fuit: qui, quamquam humanitatis parum, ruris tamen ac militiae miseriis imbuti, satis optimi rei publicae fuere. Quare constat sanctos prudentesque sensu mali promptius fieri, contraque expertes aerumnarum, dum opibus suis cunctos aestimant minus consulere (39, 26-27). 
cola 2007, 305): ausencia de discursos, excursos y otras amplificaciones y presentación individualizada de los emperadores a través de descripciones escuetas y concisas. Si bien es cierto que dicha historia imperial está narrada por medio de retratos biográficos de los distintos emperadores, con todo, se puede advertir un cambio en esta técnica en la etapa posterior a los Severos. Tal como senala Bird (1990, 87-92) las biografías de estos últimos y las de los emperadores anteriores se narran, en general, con trazos breves y se suceden rápidamente. Sin embargo, las últimas biografías imperiales, concretamente a partir de Caro y sus hijos (IX, 18) presentan un esquema narrativo donde prima el relato cronológico de los hechos. Puesto que el cambio de técnica coincide con el advenimiento de la primera Tetrarquía, cabe pensar que la propia coyuntura política que da lugar al reparto territorial del poder entre augustos y césares es la que induce al historiador a cambiar el criterio narrativo y primar los hechos sobre el retrato biográfico de los emperadores. En cualquier caso, la concisa caracterización de Diocleciano y Maximiano, los términos valorativos y los breves comentarios que desliza Eutropio a lo largo de la narración así como el silencio sobre determinadas cuestiones contribuyen a forjar una imagen de los augustos que difiere de la ofrecida por Aurelio Víctor. Para empezar, Eutropio describe la elección de Diocleciano por parte del ejército tras el asesinato de Numeriano mediante dos recursos narrativos: la inserción de una valoración negativa acerca del oscurísimo origen del nuevo augusto ${ }^{12}$ y el relato de una anécdota relativa a un hecho que también narra y comenta Aurelio Víctor (De Caesaribus 39, 13-16): el primer discurso de Diocleciano ante el ejército, discurso en el que jura no haber tramado el asesinato de Numeriano, y la muerte con su espada de Apro, autor de la trama (Breviarium 20, 1). Ambos datos desprovistos de comentarios adicionales como los que ofrece A. Víctor sobre la clemencia inusitada de Diocleciano para con los seguidores de Apro, contribuyen a forjar una imagen negativa de aquel, imagen que se ratifica en una de las escasas valoraciones intercaladas por el epitomador en el curso de la narración. Nos referimos más concretamente a un pasaje del cap. 23 en el que Eutropio, tras haber relatado las actuaciones sucesivas de Diocleciano y Maximiano contra los bagaudas en la Galia, Carausio en Britania y Aquileo en Egipto, menciona la crueldad del primero para con los vencidos ${ }^{13}$ y ello en abierta contradicción con Aurelio Víctor quien, como hemos dicho, destaca la clemencia y sabiduría de Diocleciano como rasgos destacados de su personalidad. En el relato de las restantes campañas bélicas, principalmente las guerras contra Narseo en Persia y Sapor en Armenia, cabe señalar la inserción de una anécdota que subraya la insolencia con que trató Diocleciano a Maximiano después de la derrota que éste último sufrió frente a Narseo. Tras una rápida relación del resultado positivo de las campañas militares en Oriente, Eutropio ofrece una breve descripción de la personalidad de ambos augustos. En el caso de Diocleciano priman los aspectos positivos pero la sapientia de A. Víctor aparece designada como sollertia y se insiste de nuevo en la seueritas ${ }^{14}$ del augusto. De Maximiano se destaca su naturaleza violenta y su complacencia en secundar la crueldad de Diocleciano. Sin embargo, en medio de los claroscuros que rodean la personalidad de éste úl-

12 Diocletianum imperatorem creavit, Dalmatia oriundum, vivum obscurissime natum adeo ut a plerisque scribae filius, a nonnullis Anullini senatoris libertinus fuisse credatur (19,2). Las citas de Eutropio están tomadas de la ed. de Bird, 1993.

13 Victoria acerbe usus est; totam Aegyptum gravibus proscriptionibus caedibusque foedavit.

${ }_{14}$ Diocletianus moratus callide fuit, sagax praeterea et admodum subtilis ingenii et qui severitatem suam aliene invidia vellet explere. Diligentissimus tamen et sollertissi- mus princeps et qui imperio Romano primus regiae consuetudinis formam magis quam romanae libertatis invexerit adorarique se iussit $(26,1)$. Tras la descripción de la naturaleza violenta de Maximiano, se insiste nuevamente en la crueldad de Diocleciano, hecho que también se señala en el De Mortibus Persecutorum de Lactancio: Herculius autem propalam ferus et incivilis ingenii, asperitatem suam etiam vultus horrore significans. Hic naturae suae indulens Diocletiano in omnibus est saevioribus consiliis obsecutus $(27,1)$. 
timo, en los capítulos finales pasa a primer plano la abdicación voluntaria del augusto, rasgo que, al igual que en la obra de Aurelio Víctor, merece un comentario elogioso por parte del historiador.

En general, y si bien es cierto que en la obra de Eutropio prima la técnica biográfica, en el período tetrárquico la narración sigue un esquema cronológico sazonado de escuetas anécdotas y algún breve comentario acerca de la actuación de los emperadores, esquema que se complementa en la parte final del capítulo por la descripción de los rasgos predominantes de su personalidad. Apenas encontramos digresiones ni valoraciones de los hechos que permitan conformar su interpretación de los mismos si bien, y a pesar de la brevedad, es posible captar la subjetividad de la narración a través de las anécdotas seleccionadas, la omisión de ciertos aspectos del período narrado así como la descripción de la personalidad de los emperadores y las connotaciones derivadas de la misma.

En la segunda parte de este trabajo, nos proponemos analizar una fuente literaria de carácter esencialmente retórico pero con una base histórica innegable: los Panegyrici latini, y dentro de este corpus aquellos discursos dirigidos a Maximiano, Diocleciano y Constancio. Aunque en estos documentos, la propaganda política juega un papel prioritario, el fondo histórico, como hemos senalado es innegable y, de hecho, un historiador contemporáneo como Amiano Marcelino cita los panegíricos entre sus fuentes ${ }^{15}$. Nuestro objetivo, es por tanto, señalar cuáles son los principales recursos retóricos que transmiten dicha propaganda oficial y en qué conceptos ideológicos se plasma.

\section{LOS PANEGÍRICOS LATINOS: RÉTORES AL SERVICIO DE LA PROPAGANDA IMPERIAL}

Entre los once discursos que constituyen la colección denominada Panegyrici Latini ${ }^{16}$ hemos considerado como objeto de análisis sólo los dirigidos a Maximiano (si bien Diocleciano está también presente en tales discursos) y a Constancio ya que son los que abarcan el período relativo a la primera Tetrarquía. Los panegíricos II [10] y III [11] ${ }^{17}$ fueron pronunciados en Tréveris por un rétor oriundo del lugar llamado Mamertino en presencia de Maximiano aunque en honor de los dos Augustos. El primero, datado en abril del 289, se pronunció con ocasión del aniversario de la fundación de Roma y tiene como objetivo celebrar las victorias de Maximiano sobre los bagaudas, los germanos y los piratas. El segundo, pronunciado probablemente en julio del 291, conmemora el aniversario del dies natalis de los emperadores, es decir, del día en que recibieron los títulos divinos de Iovius y Herculeus ${ }^{18}$. Por otro lado, el panegírico IV[8] fue pronunciado el uno de marzo del 297 por un rétor anónimo probablemente en Autun con ocasión de las Quinquennalia, fiestas solemnes para celebrar el nombramiento como César de Constancio Cloro; este discurso festeja, sobre todo, la campaña de Constancio en Bretaña y su victoria sobre Carausio y Alecto. Por fin, el

15 (Germani) maioraque conceptantes, pagorum omnium incolis in unum conlectis cum quadraginta armatorum milibus uel septuaginta ut quidam laudes extollendo principis iactarunt, sublati in superbiam nostra confidentius inruperunt (31.10.5).

16 Los PL son una colección de once discursos dirigidos a los emperadores Diocleciano, Maximiano, Constancio, Constantino, Juliano y Teodosio que en la tradición manuscrita se transmitieron precedidos por el Panegírico de Trajano de Plinio. Al parecer el compilador del conjunto fue el autor del último de los discursos del corpus, Pacatus Drepanius (Ronning 2007, 139-140), un rétor que tras haber sido profesor de retórica en la Galia, llegó a ser procónsul de África. La edición utilizada en las páginas que siguen es la de Lassandro y Micunco, 2000.

17 Adoptamos en la numeración de los panegíricos el criterio cronológico de Lassandro-Micunco. Los números arábigos entre paréntesis indican el lugar que los discursos ocupan en la tradición manuscrita (ibid, 59-65).

18 Vid. el pormenorizado estudio de S. d'Elia relativo a los discursos de Mamertino (en particular, 1960-61, 179-217). 
panegírico V[9] fue compuesto por Eumenio, magister memoriae de Constancio, con motivo de la restauración de las famosas Escuelas Menianas de Autun. Dado que los autores son rétores galos, los panegíricos citados van dirigidos a Maximiano y Constancio, responsables principales de las campañas desarrolladas en la Galia, Germania y Britania, si bien el elogio se hace extensivo siempre a Diocleciano y, sobre todo, al régimen, diárquico primero y tetrárquico después. La abundante bibliografía sobre el corpus ha incidido tanto en el valor histórico de los discursos como en el análisis de aspectos estilísticos y retóricos. Por nuestra parte, vamos a subrayar en las líneas que siguen el modo en que la utilización de ciertos recursos retóricos permite modelar una imagen determinada de los emperadores y transmitir un contenido político concreto (Sabbah 1984, 370-371; Ronning 2007, 191-290).

En primer lugar, hay que señalar que la tardía sistematización de obras concernientes al genus epidicticum y, más concretamente, al basilikós lógos, se plasmó en una considerable producción teórica compuesta en griego. El área occidental del imperio participó también del extraordinario florecimiento de la retórica del elogio debido a las posibilidades que brindaba la coyuntura política, social y cultural de la época si bien los discursos que se nos conservan se restringen casi únicamente al subgénero de la gratiarum actio y denotan una clara influencia de los modelos griegos (Pernot, 1993, I, 108-110). La influencia de los tratados de Menandro además de la de diversas fuentes latinas ha sido objeto de numerosos trabajos (Klotz 1911; Mesk 1912; Maguinness 1952; Del Chicca 1985 y Nixon-Saylor 1994, 14-26). Con todo, el aspecto que nos interesa subrayar es el papel de los panegiristas como portavoces de la ideología imperial y, por tanto, como educadores en un sentido amplio ya que se trata de rétores que ejercen también de oradores políticos. El hecho de que los panegíricos respondan a una estructura estandarizada, convenientemente adaptada a las circunstancias específicas de cada ocasión nos ha permitido abordar su análisis de forma conjunta e incidir en la presencia de tópicos, fórmulas y recursos que se repiten más allá de los rasgos particulares. Por otro lado, debido a que las limitaciones de este trabajo nos impiden ofrecer una exposición exhaustiva de figuras y otros recursos retóricos, nos vamos a referir sólo a aquellos que, en nuestra opinión contribuyen más decisivamente a modelar la imagen de los emperadores para poder contrastarla con la caracterización que se encuentra en el relato de los epitomadores.

De entre las que Sabbah denomina «figuras de la presencia» ${ }^{19}$, la más llamativa es, sin duda, la amplificatio, una "intensificación preconcebida y gradual de los datos naturales mediante los recursos del arte» (Lausberg 1983, 259). Tal como señala Quintiliano $(3,7,6)$ se trata de un recurso propio del genus epidicticum que se concreta en procedimientos varios (entre ellos, la comparación o la acumulación) y que puede intercalarse en cualquiera de las partes del discurso. En los panegíricos el exordio se caracteriza, en general, por la exuberancia expresiva y la solemnidad estilística, además de por el uso de los lugares comunes al uso, amplificados. Es, sobre todo, la mención de la ocasión que da lugar al discurso la que se amplifica por medio de diferentes recursos, especialmente relatos míticos, descripciones o digresiones de contenido vario. La finalidad de estos desarrollos narrativos no es puramente ornamental ya que prácticamente en todos los casos los autores establecen una relación analógica entre el relato y el tópico de partida con el fin de elogiar, bien la persona del emperador en cuestión, bien el régimen tetrárquico. Así por ejemplo, en el panegí-

19 Así las denomina G. Sabbah $(1984,381)$ porque se proponen como objetivo hacer presente el objeto del discurso al lector. 
rico II, que celebra el aniversario de la fundación de Roma, se evoca la fundación legendaria por parte de Evandro de Pallante, lugar de emplazamiento de la futura Roma, así como la estancia de Hércules en dicho lugar después de haber luchado contra Gerión. Tras el pasaje legendario cuya veracidad prueba el panegirista aduciendo la existencia del altar de Hércules en Roma, menciona a los dos Augustos y los presenta como hermanos entre sí, como restauradores y co-fundadores del imperio al tiempo que los sitúa en el mismo plano que el legendario Hércules y los primeros reyes de Roma. A través de la correspondiente analogía, el inicio del reinado de los tetrarcas se compara con el período mítico de la fundación de Roma pues los Augustos, descendientes de Júpiter y Hércules, han hecho posible la restauración del poder imperial y el inicio de una nueva $\mathrm{era}^{20}$. Además y aún en el exordio, se hace referencia a las celebraciones que tienen lugar en el templo de Hércules en Roma de modo que, a pesar de que el discurso tiene lugar en Tréveris ante Maximiano, la simbología de la capital como centro de ese imperio renovado resulta evidente. En resumen, el exordio del discurso plantea desde el inicio la idea central que se va a desarrollar en los parágrafos siguientes y subraya incluso el mensaje que se pretende transmitir a través del relato mítico y la analogía. En el resto del discurso se desarrollan conceptos o motivos planteados en el exordio a través de más alusiones a pasajes mitológicos y ejemplos de evidentia y ya en el epílogo se retoman las mismas referencias míticas del exordio y se cierra en círculo el discurso insistiendo en el mensaje central.

En el exordio del panegírico III, pronunciado con motivo del dies natalis de Diocleciano y Maximiano, Mamertino se propone demostrar el carácter divino de ambos augustos aduciendo como prueba de divinidad la actividad constante y el movimiento incesante que los caracteriza. El panegirista conmemora la lucha de Júpiter contra los Titanes, la acción destructora de su rayo o su dominio sobre las esferas celestes y el Hado así como algunas de las famosas hazañas de Hércules (la lucha contra el león Nemeo, la Hidra de Lerna, los caballos de Diomedes, Busiris y Cerbero): al igual que los dioses de los que descienden, los Augustos no disponen de un momento de descanso $^{21}$. El relato mítico se complementa con dos parágrafos en los que se relatan las acciones bélicas emprendidas por los emperadores, acciones que reflejan una actividad incesante y constituyen un trasunto de las hazañas divinas de los dioses a los que representan.

Por otro lado, la amplificación retórica del exordio del discurso IV consiste en una estereotipada descripción de la primavera que da paso a una reflexión cuasi filosófica sobre los ciclos del universo y de la historia, reflexión que se acaba convirtiendo, a través de la analogía, en una proclamación de la nueva era inaugurada por la Tetrarquía ${ }^{22}$.

Como se puede apreciar, estos relatos míticos que se insertan a partir del tópico a re, lejos de ser un mero ornamento desempeñan una importante función ideológica y estructural: subrayar motivos fundamentales de la propaganda imperial, motivos que vertebran a su vez los contenidos desarrollados en el cuerpo del discurso y que pueden resumirse como sigue: los emperadores de la Te-

20 Re vera, enim, sacratissime, merito quivis te tuumque fratrem romani imperii dixerit conditores: estis enim, quod est proximum, restitutores et, sit licet hic illi urbi natalis dies, quod pertinet ad originem populi romani, vestri imperii primi dies sunt principes ad salutem (II, I, 1-5).

${ }^{21}$ En referencia a los Augustos, el panegirista les atribuye el tópico de que lo eterno se caracteriza por el movimiento constante (Cic., De re publ. VI, 27: nam quod semper movetur, aeternum est).
22 O felix beatumque ver novo partu, iam non amoenitate florum nec viriditate segetum nec gemmis vitium nec ipsis tantum favoniis et luce reserata laetum atque venerabile, quantum ortu Caesarum maximorum! O tempus quo merito quondam omnia nata esse credantur cum eodem nunc confirmata videamus! O kalendae martiae, sicuti olim annorum volventium, ita nunc aeternorum auspices imperatorum! Quanta enim, invictissimi principes, et vobis et rei publicae saecula propagatis orbis vestri participando tutelam?! (IV, 3, 1-2). 
trarquía han dado inicio a una nueva era, han restaurado el poder imperial simbolizado por Roma y ello ha sido posible gracias al ascendiente divino de los emperadores. Dicha naturaleza sagrada se plasma, sobre todo, en la práctica de las dos virtutes imperiales más sobresalientes: la pietas y la felicitas. Además, constituye en los panegíricos un motivo central que condiciona el tono exaltado, las expresiones religiosas y, en general, el estilo solemne de los discursos, especialmente en los exordios (Ronning 2007, 156-157). Por otro lado, el recurso al mito se complementa con la mención de las gestas imperiales en una presentación generalmente antitética que pretende subrayar la grandeza y credibilidad de lo real frente al carácter legendario del mito: el panegirista insiste en que las hazańas imperiales son reales y superan en valor a los relatos míticos relativos a Júpiter y Hércules: Finguntur haec de Iove sed de te vera sunt, imperator (II, 2, 5); omittam cetera, et potissimum illud adripiam quod multis fortasse mirum videbitur et tamen re ipsa verissimum est (II, 3, 1); sed removeamus istinc fabulas imperitorum, uerum loquamur (III, 8, 4). El panegirista se apropia, en cierto modo, de una de las condiciones exigidas al historiador: la de relatar hechos verdaderos y creíbles ${ }^{23}$. En este sentido, la ficción mítica no es, tal como hemos señalado, un ornamento gratuito sino que sirve para magnificar mediante la analogía una realidad que, siendo verídica, por su carácter extraordinario supera la ficción.

Además de la amplificatio a la que nos acabamos de referir, un segundo recurso retórico que confiere plasticidad y colorido visual a estos discursos es la evidentia, es decir, la descripción viva y detallada de un objeto o de un proceso, como si se tratara de escenas vistas y vividas realmente ${ }^{24}$. En los panegíricos analizados se encuentran abundantes ejemplos de este recurso que, en cierto modo, contribuye a dar impresión de veracidad a las hiperbólicas afirmaciones que constituyen el cuerpo del discurso. En la mayoría de las ocasiones, la evidentia permite ilustrar alguna cualidad atribuida a los emperadores a través de la descripción de una escena correspondiente a alguna de las campañas bélicas dirigidas por ellos. En tales casos, la descripción funciona prácticamente a modo de testimonio visual y por ello, podría considerarse incluso como el equivalente a una pseudo-fuente en un relato histórico. Una de las virtudes que aparece descrita a través esta figura es la rapidez sobrehumana y la omnipresencia de los emperadores. Tal como afirma Mamertino en III, 3, 2 remitiendo a un motivo filosófico de tradición literaria al que ya hemos aludido ${ }^{25}$ : quidquid immortale est stare nescit, sempiternoque motu se servat aeternitas. Como ilustración de dicha cualidad, el panegirista describe la extrema diligencia de Maximiano en su lucha contra los caibones y érulos, tan rápida que no es necesaria una multitud de soldados para hacerles frente ya que él solo acude a todos los frentes ${ }^{26}$; su naturaleza divina explica también su capacidad para atender deberes civiles y militares con una celeridad sobrehumana. Es interesante constatar que el rétor recurre a menudo al verbo uideo en primera persona para atestiguar la veracidad de la descripción que ofrece al tiempo que logra reflejar la rapidez del movimiento mediante construcciones asindéticas breves o adverbios como repente, continuo o iam ${ }^{27}$. Además de la omnipresencia, la evidentia se uti-

23 En el período tardío Luciano critica en su tratado Cómo debe escribirse la historia el recurso al mito por parte de los historiadores en nombre de la objetividad, veracidad e imparcialidad que debe presidir la narración histórica (Botella Zaragoza 1990, 6-7 y ss.).

${ }_{24}$ Credibilis rerum imago quae velut in rem praesentem perducere audientes videtur (Quintiliano 4, 2, 123); ab aliis upotiposis dicitur proposita quaedam forma rerum ita expressa verbis, ut cerni potius videatur quam audiri (ibid., 9, 2, 40). Naturalmente tales imagines y descrip- tiones pueden aplicarse tanto a objetos como a personas, hechos o procesos.

25 Vid. n. 21.

26 Quid enim opus erat multitudine cum ipse pugnares, ipse omnibus locis totaque acie dimicares, ipse hosti undique et qua resisteret et qua cederet et qua fugeret occurreres, erroremque adversariis pariter ac tuis faceres, cum neque te barbari unum putarent neque milites, non dico stipatione atque comitatu sed saltem oculis sequi possent (II, 53). 
liza también para resaltar de un modo especial algunos de los loci a persona habituales en los discursos epidícticos. En el caso de Maximiano, tanto en el panegírico II como en el III se hace referencia al origen, al lugar de nacimiento y a la educación recibida. Mediante el recurso a la praeteritio, el panegirista elude mencionar la carencia de una formación en artes así como la pertenencia a un linaje y un lugar de origen ilustre; en su lugar introduce un elogio de la vida militar propio de las gentes que habitaban zonas fronterizas y militarizadas del imperio. Además, haciendo uso de la evidentia, Mamertino retrata una supuesta escena de infancia en esas zonas y evoca así la dureza de un modus vivendi que estaría en el origen de la fortaleza posterior de Maximiano ${ }^{28}$. La misma figura transmite al lector la admiración causada por el lujo del porte externo del emperador ${ }^{29}$.

En otros pasajes, los procesos que se describen a través de la mencionada figura tienen como finalidad retratar la actitud cuasi reverencial de las gentes hacia sus emperadores-dioses, incluso la de los bárbaros vencidos que, no sólo aceptan de grado el poderío romano sino que incluso se congratulan de formar parte del imperio. Son especialmente sugerentes los pasajes III, 10, 4-5 y IV, 9, 1-4. En el primero de ellos el panegirista describe un encuentro entre Diocleciano y Maximiano en Milán que, al parecer, hay que situar en el invierno del 290 o $291^{30}$. Tras descender de las montañas, Mamertino yuxtapone en dos escenas contrapuestas, como si se tratara de un díptico, el sentimiento de pavor que experimentaron en otro tiempo los habitantes de Italia al ver a Aníbal descender de los Alpes ${ }^{31}$ junto con el gozo de las gentes que en el momento actual salen al encuentro de los emperadores y los saludan cual si fueran dioses (ceremonia de la adoratio ${ }^{32}$ ). En cuanto al segundo de los pasajes citados, el anónimo autor del panegírico IV describe en primer lugar la tierra de los bátavos en el delta de Rhin y cómo sus habitantes, tras ser vencidos, esperan ser llevados como colonos a ocupar tierras desoladas por las guerras y que formaban ya parte del imperio ${ }^{33}$. En ambos pasajes, el uso de la evidentia permite al panegirista enfatizar la concordia entre ambos Augustos, la subordinación de Maximino a Diocleciano y la felicitas que experimentan los súbditos,

7 Vidimus te, Caesar, eodem die pro re publica et vota suscipere et convicta debere... Vidimus te Caesar, eodem die et in clarissimo pacis habitu et in pulcherrimo virtutis ornatu...ne Iuppiter quidem ipse tanta celeritate faciem caeli sui variat quam facile tu, imperator, togam praetextam sumpto thorace mutasti, hastam posito scipione rapuisti, a tribunali temet in campum, a curuli in equum transtulisti et rursus ex acie cum triumpho redisti, totamque hanc urbem repentina tua in hostes eruptione sollicitam laetitia et exsultatione et aris flagrantibus et sacrificis odoribus et accensis numini tuo implesti (II, 6, 3-4). Cf. también III, 4, 2; III, 8, 3; IV, 6, 1-2 etc.

28 Unde igitur ordiar? Commemorabo nimirum patriae tuae in rem publicam merita?... An quemadmodum educatus institutusque sis praedicabo in illo limite, illa fortissimarum sede legionum, inter discursus strenuae iuventutis et armorum sonitus tuis vagitibus obstrepentes? (II, 2, 2-4).

29 Trabeae uestrae triumphales et fasces consulares et sellae curules et haec obsequiorum stipatio et fulgor et illa lux dininum uerticem claro orbe complectens uestrorum sunt ornamenta meritorum pulcherrima quidem et augustissima (II, 3, 2).

30 Sobre el significado político de este encuentro vid. D’Elia, 1961, 304-307.
31 Recurre de nuevo a la evidentia al describir una escena protagonizada por madres que dejan caer de sus manos las ruecas y corren con sus hijos a refugiarse a los templos al tiempo que claman y gimen por la desgracia que se avecina (III, 10, 3).

32 Ut uero propius propiusque coepti estis agnosci, omnes agri oppleti non hominibus modo ad uisendum procurrentibus, sed etiam pecudum gregibus remota pascua et nemora linquentibus, concursare inter se agricolae, nuntiare totis uicis uisa, arae incendi, tura poni, uina libari, uictimae caedi, cuncta gaudio calere, cuncta plausibus tripudiare, dis immortalibus laudes gratesque cantari, non opinione traditus, sed conspicuus et praesens Iuppiter cominus inuocari, non aduena, sed imperator Hercules adorari (III, 10, 5).

33 Quis hoc unquam futurum, etiamsi coram uoluisset affari, deus ante uos principes persuadere potuisset quod nunc uidimus et uidemus: totis porticibus ciuitatum sedere captiua agmina barbarorum, uiros attonita feritate trepidantes, respicientes anus ignauiam filiorum, nuptas maritorum, uinculis copulatos pueros ac puellas familiari murmure blandientes atque hos omnes prouincialibus uestris ad obsequium distributos, donec ad destinatos sibi cultus solitudinum ducerentur (IV, 9, 1). 
incluso los vencidos, ante sus emperadores gracias a la pietas y la concordia que preside sus actos. En este pasaje, el dialogismo es también un rasgo adicional que contribuye a dramatizar el encuentro y reforzar el realismo de la escena ${ }^{34}$. Sin duda, algunos tópicos clave de la propaganda imperial podían ser transmitidos con gran plasticidad y viveza, a saber, la fraternitas que unía a los augustos, la divinidad que revestía a ambos, la alegría experimentada por las gentes ante la presencia de tales emperadores y la felicitas o prosperidad extendida a todo el imperio como consecuencia de su gestión (Starbatty 2007, 150-151).

Un último ejemplo de evidentia que reviste especial interés es la descripción cartográfica de $\mathrm{V}, 20$, 3- 21, 1-3. Dicho pasaje se inserta en un lugar retóricamente marcado del discurso, el final del panegírico $\mathrm{V}$, el único del corpus, por otra parte, no pronunciado en presencia de un emperador (aunque va dirigido a Constancio). El pasaje describe imágenes cartográficas grabadas o pintadas en las paredes del pórtico de las Escuelas Menianas. Tales escuelas, famosas en otro tiempo por la calidad de la formación retórica adquirida en ellas, son restauradas bajo Constancio y abren de nuevo sus puertas bajo la dirección del rétor Eumenio, magister memoriae de dicho emperador. Al final del panegírico, que contiene un elogio continuado de la función instructivo-moral de la Retórica y de la labor del rétor, se describen todas las regiones, costas, ríos, etc. que forman parte del imperio romano y reflejan su extensión y poderío ${ }^{35}$. La grandiosidad del grabado se resume en la frase final que, por otro lado, expresa explícitamente el mensaje propagandístico del discurso y da paso a la salutación final: nunc enim, nunc demum iuvat orbem spectare depictum, cum in illo nihil videmus alienum.

Un tercer elemento retórico característico de los panegíricos y útil también para la expresión de la propaganda imperial es la inserción de exempla míticos o históricos que pretenden equiparar la figura del emperador en cuestión con personajes ilustres y mostrar la superioridad de aquel. Así por ejemplo, en II, 7, 1-3 se menciona la destrucción de Cartago por Escipión después de hacer venir a Aníbal desde Italia. Maximiano es presentado como un nuevo Escipión ya que ha imitado su táctica de destrucción del enemigo (neque enim minorem laudem magnarum rerum aemuli quam ipsi merentur auctores). En II, 9, 4 los Augustos gobiernan el imperio como los Heráclidas Lacedemonia. Aunque generalmente el exemplum se reduce a la alusión histórica y la comparación, en III, 9, 4 se desarrolla con especial amplitud. En dicho capítulo, que recuerda la gesta de Aníbal en los Alpes durante la segunda guerra púnica, el panegirista relata los hechos presentándolos en forma de díptico: más allá de la clara alusión al relato liviano (Livio XXVI, 9), el rétor reproduce dramáticamente una escena del pasaje histórico para contrastarla a continuación con el hecho actual protagonizado por los emperadores ${ }^{36}$. De este modo, tal como señalan Lassandro y Micunco (2000, 112), Mamertino inserta el acontecimiento presente en la tradición histórica romana y

\footnotetext{
34 Clamare omnes prae gaudio (...): "vides Diocletianum? Maximianum uides? Ambo sunt, pariter sunt! Quam iunctim sedent! Quam concorditer colloquuntur! Quam cito transeunt!" (III, 11, 4).

35 Siquidem illic, ut ipse vidisti, credo, instruendae pueritiae causa, quo manifestius oculis discerentur quae difficilius percipiuntur auditu, omnium cum nominibus suis locorum situs spatia intervalla descripta sunt, quidquid ubique fluminum oritur et conditur, quacumque se litorum sinus flectunt qua vel ambitu cingit orbem vel impetu inrumpit Oceanus. Ibi fortissimorum imperatorum pulcherrimae res gestae per diversa regionum argumenta recolantur dum calentibus semperque venientibus victoria-
}

rum nuntiis revisuntur gemina Persidos flumina et Libyae arva sitientia et convexa Rheni cornua et Nili ora multifida; dumque sibi ad haec singula intuentium animus adfingit aut sub tua, Diocletiane Auguste, clementia Aegyptum furore posito quiescentem aut te,Maximiane invicte, perculsa Maurorum agmina fulminantem aut sub dextera tua, domine Constanti, Bataviam Britanniamque squalidum caput silvis et fluctibus exserentem aut te, Maximiane Caesar Persicos arcus pharetrasque calcantem.

36 Tras la introducción de la comparación por el panegirista (Tum, si fortunae causaeque Hannibalis ac uestrorum itinerum comparentur, quanto haec uestra dis hominibusque acceptiora sunt!) el resto del capítulo evoca mediante 
subraya la grandeza del mismo, superior a las hazañas de otros tiempos. Además, mediante el uso de la evidentia enfatiza la antítesis entre la amarga imagen del temor romano ante Aníbal en el pasado y el gozo que provoca el encuentro entre los Augustos en Milán. En otros pasajes, sin llegar a narrar episodios ilustrativos, el panegirista hace uso de antonomasias elogiosas o perífrasis peyorativas para marcar el contraste entre los emperadores y sus enemigos. Así, en II, 14, 2 el rétor afirma que no hay necesidad de Camilos, Maximos, Curios o Catones ya que los augustos ofrecen con sus gestas ejemplos inmejorables para imitar. Por otro lado, Carausio y Alecto, usurpadores del poder romano en Britania son designados como pirata (II, 12, 1; IV, 12,1), archipirata (IV, 12, 2), vexillarius latrocinii (IV, 12, 5). Exempla, antonomasias y perífrasis sirven para marcar la antinomia entre el imperator invictus y toda clase de opositores (Sabbah 1984, 382-383; Lassandro 2006, 106-110).

Junto a los recursos más específicamente retóricos, cabe enumerar también ciertos procedimientos narrativos que los panegiristas comparten con los historiógrafos. Nos referimos a la inserción de comentarios personales, digresiones y al afán de aportar el testimonio personal como fuente para garantizar la credibilidad de lo narrado. Este último rasgo es, probablemente, el que por su frecuencia resulta más llamativo. A pesar de que el elogio desmesurado pretende conformar una imagen idealizada de los emperadores, los panegiristas insisten en presentar el relato como verídico $\mathrm{y}$ aluden con frecuencia al testimonio visual: sed removeamus istinc fabulas imperitorum, uerum loquamur (III, 8, 4); interim tamen, dum mibi ante oculos pono cotidiana colloquia (III, 12, 3); quamquam multa mihi ex illis... transeunda sunt ac potissimum ea quibus officio delati mihi a diuinitate uestra honoris interfui (IV, 2, 1); ne meis quoque stipendiis uidear gloriari, sufficit conscientiae meae illa uidisse (IV, 2, 1); quis hoc unquam futurum, etiamsi coram uoluisset affari, deus ante uso principes persuadere potuisset quod nunc uidimus et uidemus (IV, 9, 1); omnes enim illos, ut audio, campos atque colles non nisi taeterrimorum hostium corpora fusa texerunt (IV, 16, 3). En esta línea, la evidentia, aunque aporta, sobre todo, dramatismo constituye también un recurso para dar vida al relato y presentarlo como un testimonio extraído de la realidad.

El uso de digresiones o la inserción de opiniones personales de contenido filosófico es otro de los elementos que comparten los panegíricos con la narración histórica. El único pasaje que contiene un comentario personal sobre el período histórico anterior a la Tetrarquía aparece en el panegírico IV, que es, entre los discursos analizados, el que presenta un estilo narrativo más cercano al historiográfico por el protagonismo que confiere el panegirista a la descripción de la campaña bélica de Britania dentro de la exposición de facta. En dicha digresión, el panegirista, haciendo uso de un estilo salustianeo, atribuye al hado o a la imprevisión del gobierno la ruptura de la unidad imperial bajo el emperador Galieno quien, al igual que en el De Caesaribus de Aurelio Víctor marca el punto álgido de la decadencia iniciada por los emperadores-soldado ${ }^{37}$. El anónimo rétor coincide con la fuente histórica al afirmar que en dicho período se perdieron provincias y ciudades al tiempo que cundía por doquier el dolor. Frente a este cuadro lúgubre el autor contrapone la labor de los tetrarcas, labor que había permitido recuperar diversas regiones del imperio a excepción de Britania cuya conquista consuma finalmente Constancio ${ }^{38}$.

la evidentia nuevamente el temor que las familias campesinas experimentaron ante la vista del ejército de Aníbal así como la huída de las madres con sus hijos a los templos. Dicho cuadro y la referencia explícita a las derrotas de Cannas y Trasimeno contrastan con el gozo que suscita la venida y el encuentro de ambos Augustos (III, 10, 2-4).
37 En 33, 3 Aurelio Víctor afirma sobre Galieno: rem romanam quasi naufragio dedit cum Salonino filio. Al igual que el panegirista, el epitomador subraya la pérdida de Tracia, Macedonia, partes de Asia, Mesopotamia y la existencia de conflictos bélicos en casi todas las provincias. 
Otra valoración crítica de los emperadores anteriores se encuentra en IV, 14, 1 donde el panegirista afirma, aduciendo como autoridad a Frontón, que los príncipes anteriores gobernaron la república sin abandonar Roma y sin pisar el campo de batalla. Constancio, sin embargo, lejos de ser un mandatario de gabinete, se erige en impulsor y guía de la expedición a Britania ${ }^{39}$.

Más frecuentes son los comentarios y digresiones de carácter filosófico. En IV, 1, 1-3, el panegirista, al igual que A. Víctor (De Caesaribus 39, 24-25) justifica la constitución del régimen tetrárquico a partir de las necesidades derivadas de la expansión territorial del imperio (gubernacula maiora quaerebat aucta atque augenda res publica), y afirma que la repartición cuatripartita del poder constituye una imitación de los fenómenos más grandiosos del ciclo vital del universo. Esta simbología del número cuatro confluye en el pasaje citado con la luz benefactora que irradian los astros encabezados por el Sol, luz a la que supera la Romana lux expandida por los emperadores sobre todo el imperio.

Por otra parte, la mayor parte de los comentarios que insertan los panegiristas en diversos pasajes hacen referencia a la naturaleza divina de los Augustos y tienen como objetivo probar la divinidad de Diocleciano y Maximiano tras recibir la denominación de Ioveo y Hercúleo, respectivamente. Así, se subraya con insistencia el incesante movimiento de lo eterno (III, 13 ), la cualidad superior de las almas celestes, y por tanto las de los emperadores, no sometidas a sentimientos bajos y ruines como la envidia (III, 6, 4-5), las leyes imperiosas que rigen el movimiento de los astros a lo largo de los siglos frente a la independencia y amplitud de miras de los emperadores (III, 13, 2).

Una digresión interesante es la que ocupa el capítulo 12 del panegírico V. En ella el rétor Eumenio reflexiona sobre los distintos tipos de recompensas que una persona puede lograr a lo largo de su vida a la vez que desprecia el afán de lucro en sí mismo. Es llamativa la mención de los comerciantes sirios, indios o délicos como representantes de la búsqueda de ganancias meramente materiales frente a quienes como Eumenio valoran el mérito personal como recompensa superior. Pero son los comentarios del autor acerca de la importancia del estudio de las artes los que añaden un carácter particular al discurso V. En realidad, todo el panegírico, pronunciado por Eumenio como una gratiarum actio dirigida a Constancio por nombrarle director de las Escuelas Menianas, constituye un elogio de la labor llevada a cabo por los rétores así como de la educación recibida en las escuelas. Además de subrayar las salidas profesionales de los jóvenes instruidos en las artes, Eumenio pone en evidencia que uno de los objetivos centrales de la retórica es pronunciar discursos de agradecimiento, elogiar la labor de sus emperadores y ensalzar la grandeza del imperio ${ }^{40}$. En otras palabras, Eumenio es consciente de la importancia de su labor como educador moral y como portavoz de la ideología imperial ante el pueblo ${ }^{41}$.

38 Minus indignum fuerat sub principe Gallieno quamuis triste harum prouinciarum a Romana luce discidium. Tunc enim siue incuria rerum siue quadam inclinatione fatorum omnibus fere membris erat truncata res publica... Nunc uero toto orbe terrarum non modo qua Romanus fuerat uirtute uestra recepto sed etiam qua hostilis edomito... (IV, 10, 4).

39 IV, 10, 3-4. Por otra parte, el capítulo termina con una reproducción en estilo directo de la reacción enardecida de los soldados al verse guiados por el em- perador, palabras que según Galletier 2003, 93 constituyen una paráfrasis de las de César en Lucano V, 578 ss.

40 (...)interest etiam gloriae quam tanti principles tot uictoriis ac triumphis merentur ut ingenia quae canendis eorum uirtutibus excoluntur non intra priuatos parietes, sed in publica ostentatione et in ipso urbis istius ore negetentur $(\mathrm{V}, 9,1)$.

${ }^{41}$ En este sentido, son ilustrativos los pasajes V, 8, 1-2 y V 10, 1; en el primero de ellos se destaca explí- 


\section{CONCLUSIONES: RETÓRICA Y PROPAGANDA IMPERIAL}

Tras un somero acercamiento a los dos principales epitomadores del s. IV y a algunos de los panegíricos incluidos en el corpus de los PL, hemos querido subrayar el papel fundamental que desempeña la retórica en dichas fuentes por lo que hace a la transmisión de una determinada imagen de los emperadores que inauguraron el sistema tetrárquico.

Entre los epitomadores, Aurelio Víctor es, sin duda, quien logra a través de las numerosas digresiones que jalonan su relato una interesante fusión entre técnica historiográfica y relato biográfico. A través de tales digresiones ofrece una visión de la historia imperial dividida en etapas a lo largo de las cuales se suceden los acontecimientos mediante la yuxtaposición de cuadros dramatizados en los que se alternan periodos de decadencia y prosperidad que se repiten cíclicamente. Además de las digresiones que sirven para delimitar tales etapas, otro buen número de ellas introducen en la narración las valoraciones morales del autor que, como buen imitador de Salustio, subordina el devenir histórico a las actuaciones de los protagonistas centrales y a sus vitia y virtutes. En este sentido, en el De Caesaribus se ofrece una imagen positiva de Diocleciano apoyada en las siguientes virtutes: sapientia, diligencia, clemencia y moderación para con los vencidos y los subordinados a él. Al igual que en los panegíricos, también Aurelio Víctor subraya la concordia como virtud que define la relación entre los tetrarcas a la vez que la explica por la supremacía indiscutible de Diocleciano al que todos consideran como una especie de padre. Aunque en más de una digresión el epitomador expresa su alta concepción de la cultura y su visión de la formación en artes como medio de ascender en el cursus honorum de la época, ello no le impide reconocer en Diocleciano, a pesar de su condición de soldado, un talento innato y, como consecuencia de ello, una gestión eficaz en la tarea de gobierno. El único rasgo negativo que le atribuye es el lujo externo y el boato del que se revistió y que era especialmente visible en el ceremonial de la adoratio. De Maximiano sólo destaca su natural lujurioso y la carencia de formación.

Eutropio, a través de una narración más escueta y desprovista casi de digresiones, ofrece un retrato un tanto diverso de Diocleciano. Desde el comienzo señala su oscurísimo origen y en lugar de la clementia que le atribuía A. Víctor, destaca su saevitia, tanto en el episodio de Apro como en su comportamiento con los vencidos en Egipto (IX, 23). Aunque también le atribuye la puesta en práctica de un lujoso ceremonial regio, con todo, en la valoración final subraya la diligencia de su gestión política y el mérito de una renuncia voluntaria al poder. Ambos epitomadores atribuyen la instauración de la Tetrarquía a las necesidades coyunturales derivadas de un imperio extenso y sometido a constantes conflictos y no emiten juicios valorativos del sistema como tal.

En los panegíricos, por otra parte, la Tetrarquía se ensalza en alguna ocasión explícitamente pero mayormente de forma indirecta a través del elogio a los Augustos. A través de recursos retóricos varios se les representa como restauradores de un poder imperial unificado que en el pe-

citamente la disposición favorable de los emperadores hacia el cultivo de los estudios literarios por ser conscientes de su importancia para la educación en valores: Credo, igitur, tali Caesar Herculius et aui Herculis et Herculii patris instinctu tanto studium litterarum fauore prosequitur ut non minus ad prouidentiam numinis sui existimet pertinere bene dicendi quam recte faciendi disciplinas et pro diuina intellegentia mentis aeternae sentiat litteras omnium fundamenta esse uirtutum, utpote conti- nentiae, modestiae, uigilantiae, patientiae magistras. En el segundo, se pone de manifiesto el vínculo directo entre el aprendizaje de la retórica y su función al servicio de la ideología imperial: (...) Ibi adolescentes optimi discant, nobis quasi solemne carmen praefantibus, maximorum principum facta celebrare (quis enim melior usus est eloquentiae?) ubi ante aras quodammodo suas, Iouios Herculiosque audiant praedicari Iuppiter pater et Minerua socia et Iuno placata. 
ríodo previo se hallaba debilitado y en decadencia. Aunque, como hemos señalado los discursos analizados van dirigidos a Maximiano y a Constancio, Diocleciano está omnipresente en todos ellos: los panegiristas ponen en evidencia la subordinación de los demás tetrarcas a este último y ponen un especial énfasis en destacar la eficacia del sistema tetrárquico para la gestión de los numerosos conflictos bélicos. A pesar de la mencionada dependencia para con Diocleciano, se insiste constantemente a través de los recursos retóricos enumerados en el trabajo en la práctica de determinadas virtutes por parte de los Augustos, especialmente, la fraternitas, la concordia y la pietas, cualidades extraordinarias que se explican por la grandiosidad que les confiere su naturaleza divina. Naturalmente en los panegíricos la imagen imperial alcanza un grado de idealización tal que no sería exagerado considerar dichos productos oratorios como specula principis. Esta función de ilustración moralizante que desempeña también el discurso que en la tradición manuscrita encabeza el corpus de los PL, el Panegírico de Trajano, se logra fundamentalmente gracias al uso de recursos retóricos tales como la evidentia, la amplificatio y la analogía. Tales recursos a través de un entramado de imágenes mítico-legendarias y una cuidada selección de escenas dramatizadas, transforman la realidad y la elevan a un plano modélico e ideal. Al mismo tiempo, la creación de estos modelos regios contrasta por antítesis con la vejación a través de la vituperatio de la figura del enemigo, ya sea interno, ya externo, cuestión de la que no nos hemos ocupado (Rodríguez Gervás 2008, 150-165; Lassandro 2006, 102-106). En este sentido, las historias abreviadas presentan, en apariencia al menos, un grado mayor de objetividad pero en la medida en que hacen uso también de determinados recursos retóricos, contribuyen a crear imágenes imperiales modélicas o repudiables de ciertos emperadores. Como afirma Dufraigne a propósito de A. Víctor «son originalité est d'avoir voulu faire de son abregé, non pas un simple résumé des faits, mais une sorte de traité de morale et de politique à l'usage des hommes au pouvoir» (2003, XXV). En definitiva, breviarios y panegíricos se erigen, a través de la retórica, en instrumentos eficaces para difundir una determinada ideología imperial.

\section{BibliografíA}

BaneHich, Th., 2011, «The epitomizing tradition in late Antiquity», en: J. Marincola (ed.), A Companion to Greek and Roman Historiography, vol. I, 305-312.

Bird, H.W., 1984, Sextus Aurelius Victor. A Historiographical Study, Liverpool.

—, 1994, Aurelius Victor: De Caesaribus, Liverpool university Press.

Botella Zaragoza, J., 1990, Luciano: Obras III. Cómo debe escribirse la historia, Madrid: Gredos.

Cizek, E., 1995, Histoire et historiens à Rome dans l'Antiquité, Lyon.

Corsaro, F., 1970, Lactantii de mortibus persecutorum, CSEL 19/27, Catania.

Chicca, F. del , 1985, «La struttura retorica del Panegirico latino tardoimperiale in prosa: teoria e prassi», Annali della Facoltà di Lettere e Filosofia dell'Università degli studi di Cagliari 6, 79-113.

D’Elia, S., 1961, "Ricerche sui Panegirici di Mamertino a Massimiano», Annali della Facoltà di Lettere e Filosofia dell'Università di Napoli 9, 121-139.

Dufraigne, P., 2003², Aurelius Victor: De Caesaribus, Liverpool University Press.

Falque, E., 1999, Eutropio: Breviario. Aurelio Victor: Libro de los Césares, Madrid: Gredos.

Galletier, E., 1949, Panégiriques latins, I-III, Paris: Les Belles Lettres.

Gorman, E., 2007, «The politics of sallustian style» en: J. Marincola (ed.), A Companion to Greek and Roman Historiography, vol. II, 379-384

KLotz, A., 1911, «Studien zu den Panegyrici Latini, III», Rheinisches Museum 66, 513-572.

Lassandro, D. y Micunco, G., 2000, Panegirici Latini, Torino: UTET. 
Lassandro, D., 2006, «L'imperator invictus in alcuni testi tardoantichi», Classica et Christiana 1, 99-110.

Lausberg, H., 1983, Manual de retórica literaria, Madrid: Gredos.

Lomas, F. J., 1988, "Propaganda e ideología. La imagen de la realeza en los Panegíricos Latinos», en: J. M. Candau Morón, F. Gascó, A., Ramírez de Verger (eds.), La imagen de la realeza en la Antigüedad, Madrid: Coloquio, 141-163.

Maguinness, W. S., 1933, "Locutions and formulae of the Latin Panegyrists», Hermathena 48, 117-138.

Marincola, J. (ed.), 2007, A Companion to Greek and Latin Historiography, Wiley-Blackwell.

Matthews, J., 2011, «The emperor and his historians» en: J. Marincola (ed.), A Companion to Greek and Roman Historiography, vol. I, 290-304.

Mause, M., 1994, Die Darstellung des Kaisers in der lateinischen Panegyrik. Sttutgart: F. Steiner

Mesk, J., 1912, «Zur Technik der lateinischen Panegyriker», Rheinisches Museum 67, 569-590.

Moreno, I., 1997, "Los autores de resúmenes» en: C. Codońer (ed.), Historia de la literatura latina, Madrid, 700-709.

Nixon, C. E. V. y Saylor Rodgers, B., 1994, In praise of later Roman emperors, Berkeley-Los AngelesOxford: University of California Press.

Отоn Sobrino, E., 2002, "Creencia y estilo en Salustio», Cuadernos de Filología Clásica. Estudios Latinos, 22:2, 363-389.

Pernot, L., 1993, La rhétorique de l'éloge dans le monde gréco-romain, 2 vols., Paris: Institut des Études Augustiniennes.

RatTi, S., 1996, Les empereurs romains d'Auguste à Dioclétien dans le Bréviaire d'Eutrope, Annales Littéraires de l'Université de Franche-Comté.

Rodríguez Gervás, M. J., 2008, «La retórica del siglo IV. Espacios de integración y exclusión del bárbaro», Studia historia. Historia antigua 26, 149-165.

Ronning, C., 2007, Herrscherpanegyrik unter Trajan und Konstantin, Tübingen: JCB Mohr.

SabBah, G., 1984, «De la rhétorique à la communication politique: les Panégyriques Latins», Bulletin de l'Association Guillaume Budé 43, 363-388.

Starbatty, A., 2007, «Kaiser und Gott in den Panegyrici Latini», Antike und Abendland 53, 141-165.

TejA, R., 1982, Lactancio. Sobre la muerte de los perseguidores, Madrid: Gredos. 